\title{
Observation of posterior corneal vesicles with in vivo confocal microscopy and anterior segment OCT
}

This article was published in the following Dove Press journal:

Clinical Ophthalmology

22 October 2010

Number of times this article has been viewed

\author{
Ryou Watanabe \\ Toru Nakazawa \\ Nobuo Fuse \\ Department of Ophthalmology, \\ Tohoku University Graduate School \\ of Medicine, Sendai, Japan
}

\begin{abstract}
The histopathology of posterior corneal vesicles (PCV) has not yet been revealed. A 15-year-old girl, who was diagnosed by slit-lamp microscopy as PCV, was examined using specular microscopy, in vivo confocal microscopy, and anterior segment OCT (optical coherence tomography). Anterior segment OCT showed that the thickness of both corneas was within normal limits. At the same time, in vivo confocal microscopy revealed endothelial cells in the rounded dark areas, acellular hyporeflective layers on the Descemet's membrane, and hyperreflective linear lesions. These findings were not reported previously by slit-lamp and specular microscopy. The abnormal findings only existed at the Descemet's membrane and corneal endothelial layer. Previous reports dealing with posterior polymorphous dystrophy (PPMD) examined using in vivo confocal microscopy reported almost the same findings, suggesting that PCV and PPMD may be the same at the microstructural level.
\end{abstract}

Keywords: cornea, Descemet's membrane, imaging

\section{Introduction}

In 1924, Schnyder noted unilateral posterior vesicular lesions of the cornea as posterior herpes of the cornea. ${ }^{1}$ However, in 1981, Pardos proposed a new concept of band-shaped structures at the level of the corneal posterior surface. ${ }^{2}$ These were called posterior corneal vesicles (PCV) and were different from posterior herpes of the cornea as previously described. PCV is an uncommon, frequently asymptomatic, unilateral, noninherited disorder, which affects the corneal endothelium and Descemet's membrane. The lesions show horizontally parallel vesicles which contain small, numerous, roundish vacuoles at the posterior surface of the cornea. ${ }^{2}$

PCV has been previously diagnosed and reported by specular microscopy. ${ }^{2,3}$ However, the histopathology of PCV remains unknown. The condition of PCV is stable, ${ }^{2}$ and the corneal transplantation for PCV was not required and the pathological analysis for PCV was not performed. Here, in order to clarify the microstructure of $\mathrm{PCV}$, we performed the imaging of PCV by in vivo confocal microscopy (Heidelberg Retina Tomograph II, Rostock Cornea Module [HRTII-RCM]; Heidelberg Engineering, Dossenheim, Germany) and anterior OCT (Visante ${ }^{\mathrm{TM}} \mathrm{OCT}$; Carl Zeiss Meditec, Dublin, CA).

\section{Case}

A 15-year-old girl was referred to the Tohoku University General Hospital because of a suspicion of corneal dystrophy. On the right eye, slit-lamp examination revealed a horizontal band-shaped structure which contained small vesicles (Figure 1A, C). 

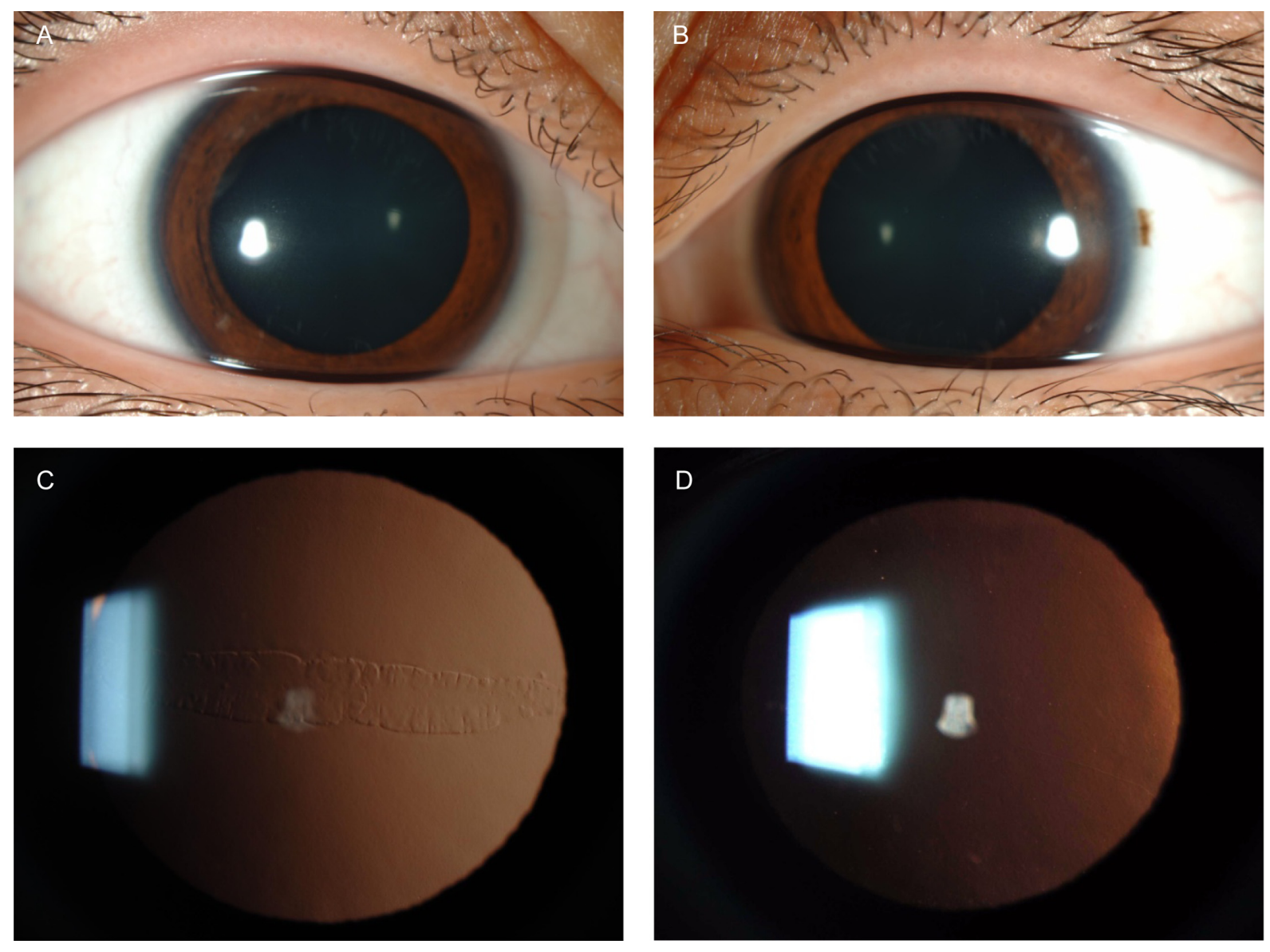

Figure I Observation using slit-lamp microscope. A) and C) affected eye. B) and D) normal eye.

The left eye was entirely normal (Figure 1B, D). Her mother's cornea had no abnormal findings. Specular microscope (Konan Noncon Specular microscope SP9000; Konan Medical, Inc., Hyogo, Japan) showed that the density of the corneal endothelium and the coefficient of variation were $1331,1060,1275 \mathrm{cells} / \mathrm{mm}^{2}$ and $0.36,0.67$, 0.35 at the superior, middle, inferior section, respectively. At the middle area, the shape of the cell was irregular and some parts contained dark areas and bright spots inside the endothelium. In contrast, in the left eye, the density of the central corneal endothelium and coefficient of variation were $2941 \mathrm{cells} / \mathrm{mm}^{2}$ and 0.33 , and there were no abnormal findings. The patient was diagnosed as PCV. HRTII-RCM revealed that three different layers were clearly separated in the epithelial layer (superficial, wing, and basal cell layer) on the right eye and suggested that the patient had well-differentiated epithelial cells. In the subbasal nerve plexus layer, the number, bifurcation, and thickness of the nerves showed similar appearance (Figure 2A) to the left eye (Figure 2B), and no inflammatory cells were detected. In the substrate layer, we detected the normal number of keratocytes and neither Langerhans cells nor round leukocytes were detected, suggesting no inflammatory response in the stromal layer. Furthermore, close to the Descemet's membrane, the cell appearance and the number of the posterior stromal cells look normal (Figure 2C, D). In the Descemet's membrane layer, an acellular hyporeflective layer (Figure 2E, black arrows) and a hyperreflective linear lesion (Figure 2E, white arrows) were clearly detected (Figure 2E) because of winding the Descemet's membrane. In the endothelial layer, the various sizes of endothelial cells were observed on the vesicle area (Figure $2 \mathrm{~F}$, white arrows). In some endothelial cells, bright deposits of endothelial cells were observed (Figure 2F, black arrow). The rounded dark areas in the endothelial layer, which were also detected by specular microscopy, were observed more clearly by HRTII$\mathrm{RCM}$. Inside the dark area, probably protruded hypertrophy of Descemet's membrane, the monolayer of endothelial cells was observed (Figure 2G, white arrow). The left cornea showed that the margins of the endothelial cells were clear, the shapes of the cells stayed hexagonal, and the sizes of the cells were generally consistent (Figure 3A, B). All images 

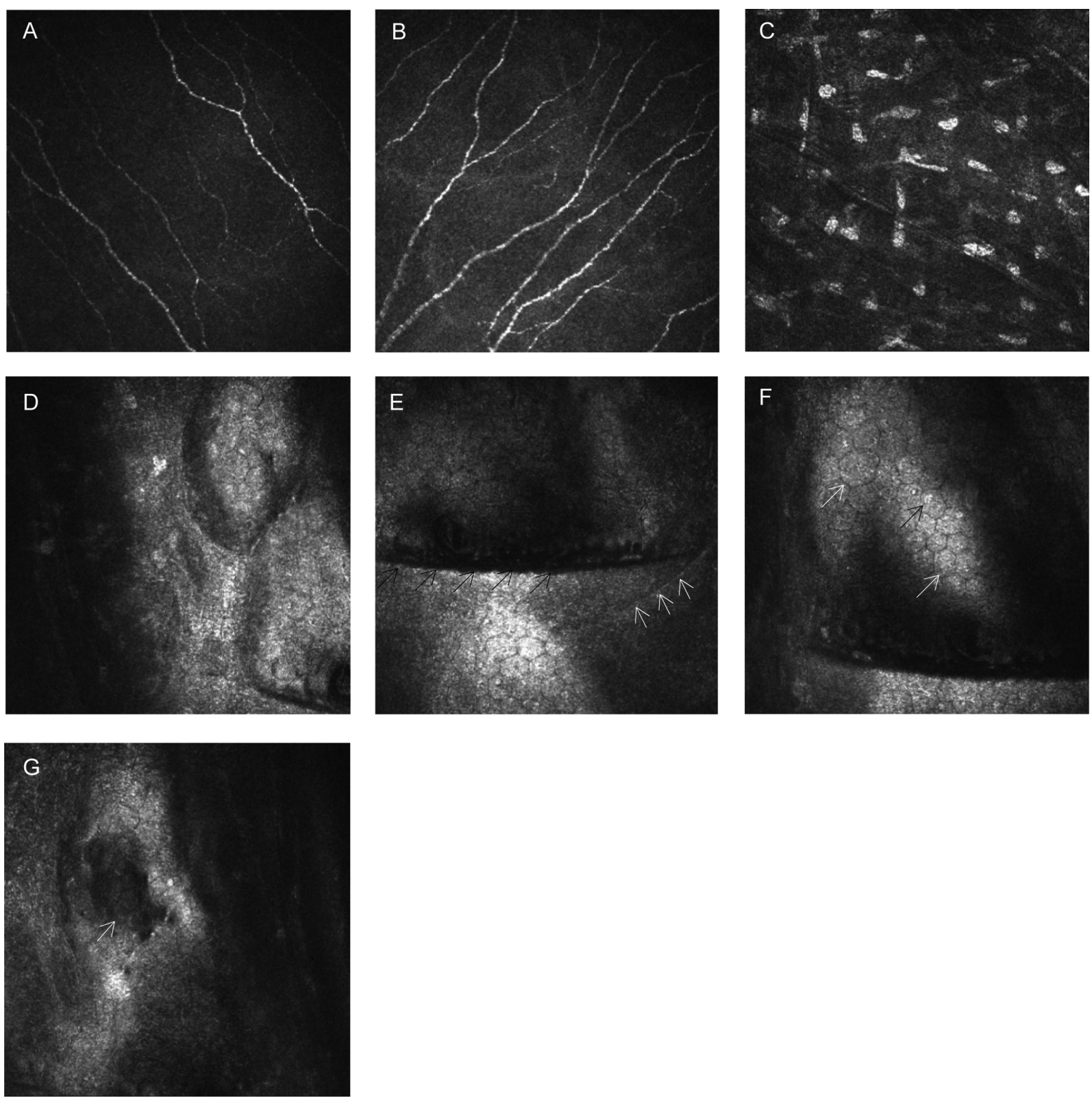

Figure 2 In vivo confocal microscopy showed that at the subbasal nerve plexus layer, number and thickness of the nerve were not different between $\mathbf{A}$ ) right eye and B) left eye. C) The number of the keratocytes was normal at posterior stroma $(524 \mu \mathrm{m})$. D) Next to the corneal endothelial cell, keratocyte of the posterior stroma was not hyperreflective (the picture was captured from oblique) $(523 \mu \mathrm{m})$. E) An acellular hyporeflective layer (black arrows) and a hyperreflective linear lesion (white arrows) were seen $(526 \mu \mathrm{m})$. F) Endothelial cells of various shapes (white arrows) $(526 \mu \mathrm{m})$ and hyperreflective nuclear of the corneal endothelial cells (black arrow) $(5 \mathrm{I} 8 \mu \mathrm{m})$ were observed. G) Endothelial cells in the rounded dark area $(547 \mu \mathrm{m})$.

of the Descemet's membrane and endothelial layer were captured at the center of the cornea.

On the right eye, anterior OCT revealed that the edge of vesicles on the endothelial layer was prominent toward the anterior chamber (Figure 4A, white arrows), and the lesions of prominent edge were also recognized by slit-lamp examinations (Figure 4B, white arrows). The central corneal thickness of the right and left eye was $572.6 \pm 3.1$ and $552.0 \pm 8.2 \mu \mathrm{m}$, respectively. In both the cases, thickness was almost similar and within normal limits.

\section{Discussion}

PCV is very similar to posterior polymorphous dystrophy (PPMD) and it is difficult to differentiate these diseases using slit-lamp microscope and specular microscope. However, PCV is affected unilaterally and is a noninherited disease, enabling the diagnosis of PCV in this case. Differential diagnoses of PCV are listed as corneal guttata, congenital glaucoma, and forceps injury during the delivery. In this case, there were no characteristic findings of corneal guttata, which are titian-colored deposits at the central cornea, and 

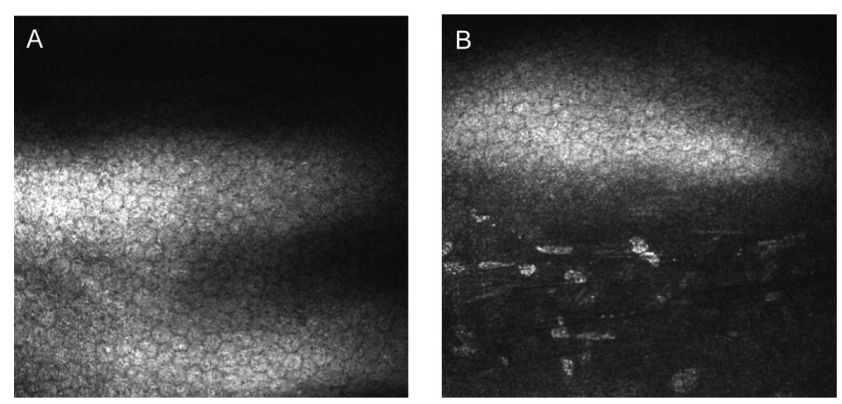

Figure 3 A) In vivo confocal microscopy showed that the left corneal endothelial cell showed the normal appearance. B) The image was captured obliquely and showed no abnormality of keratocytes in the adjacent corneal stroma to the endothelium.

brown deposits, which cause the 'beaten-metal appearance' at the posterior corneal surface. Delivery with forceps was ruled out due to no abnormality on the corneal surface. PCV is a unidentified virus-like structure in the place of the herpes cornea posterior. Therefore, the diagnosis of PCV was straightforward.

As far as we know, this is the first report describing the details of the in vivo microstructures of PCV using in vivo confocal microscopy. HRTII-RCM revealed endothelial
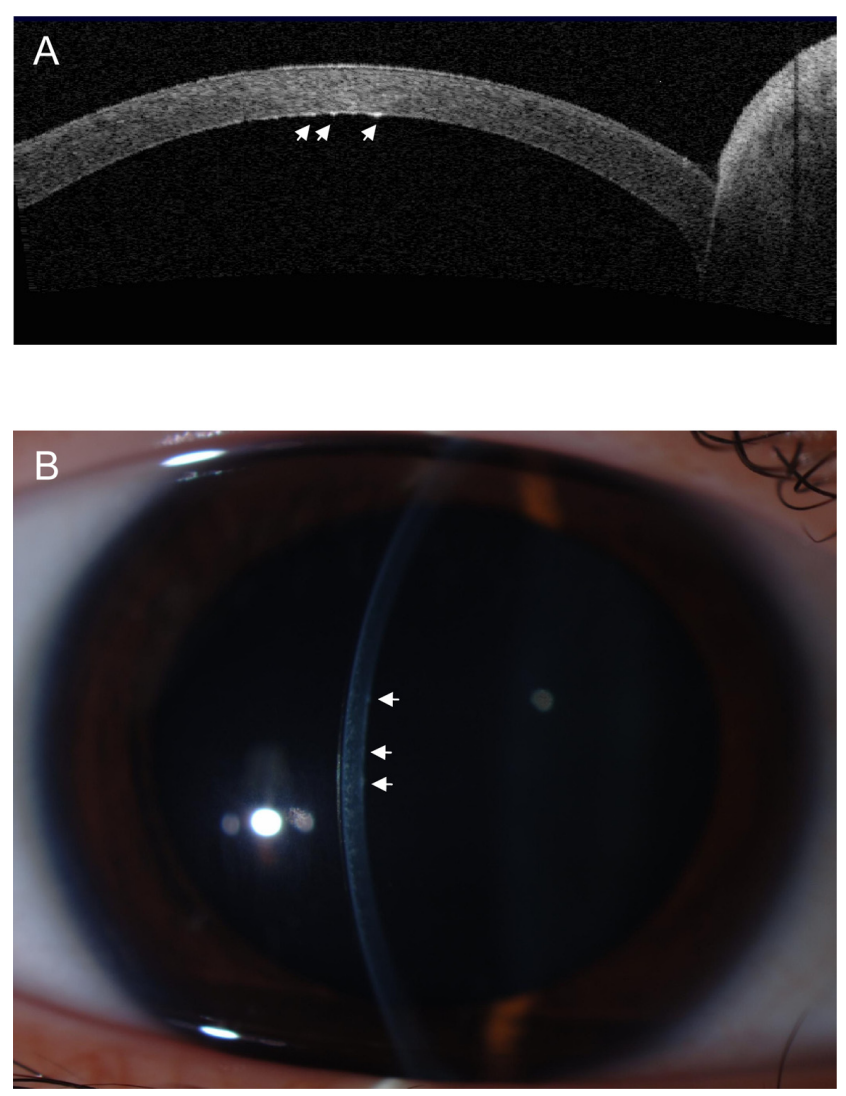

Figure $4 \mathrm{~A}$ ) Protuberance (white arrows) toward the anterior chamber was observed with anterior OCT on right eye. B) Slit-lamp microscope findings. White arrows indicated that the protuberance was located at the same places when compared with the OCT observation. cells in the rounded dark areas, acellular hyporeflective layers, and hyperreflective linear lesions. Usually, Descemet's membrane is not visualized in normal subjects. The winding of the Descemet's membrane is not detected in the normal subjects usually. And this winding of Descemet's membrane is one of the characteristic findings with this disease. So in this report, we can detect clearer thickened membranes which were not reported previously using slit-lamp and specular microscopes. ${ }^{2,3}$ On the other hand, endothelial cells which contained bright deposits at affected areas as well as endothelial cells of various shapes and focal vesicular lesions were also observed. These characteristic appearances were observed in the previous reports with specular microscope. ${ }^{2}$ Furthermore, HRTII-RCM can reveal additional information because HRTII$\mathrm{RCM}$ enables us to obtain images of the various corneal layers easily using confocal techniques. We routinely get images including superficial, wing, and basal cell layer of epithelium, subbasal nerve plexus layer, Bowman's membrane, stromal layer (anterior [100-200 $\mu \mathrm{m}$ ], middle [250-350 $\mu \mathrm{m}$ ], posterior [400-500 $\mu \mathrm{m}]$ ), Descemet's membrane layer, and endothelial layer. We found that the lesions close to the corneal endothelial cell and Descemet's membrane overlying PCV area showed no inflammatory responses like the proliferation of keratocytes, or the recruitment of Langerhans cells and leukocytes. These data suggest that the epithelium and stroma overlying the PCV lesion of this patient were within normal limits. On the other hand, in this study, we recognized that Descemet's membrane was winding and the monolayer endothelial cells were detected inside the rounded dark areas. These findings suggest that the hypertrophy of Descemet's membrane was involved in the pathogenesis of $\mathrm{PCV}$.

We compared the findings for PCV with PPMD using in vivo confocal microscopy. Both findings were similar. There have been some papers describing PPMD using in vivo confocal microscopy..$^{4-7}$ HRTII-RCM showed that in this case abnormal findings were detected at only corneal endothelial cells and Descemet's membrane. A comparison with previous reports shows that some findings were consistent with PPMD: acellular hyporeflective layers, hyperreflective linear lesions, endothelial cells containing bright nuclei, varied cell shapes, endothelial cells inside the rounded dark areas, focal vesicular lesions, and hyperreflective areas around the rounded dark areas. Other findings were different: the increased number and density of the posterior keratocytes in one case among six cases,${ }^{4}$ the thickened nerve at the Bowman's membrane, ${ }^{5}$ and needle-like lesion in the stroma with few keratocytes. ${ }^{7}$ However, these findings may suggest that one case with PPMD associated with inflammations. 
In the right cornea of this case, the density of the corneal endothelial cells had already decreased to $\sim 1000$ cells $/ \mathrm{mm}^{2}$ at the center of the cornea. Generally, the density of corneal endothelial cells is more than 3000 cells $/ \mathrm{mm}^{2}$ for patients of the same age. ${ }^{8}$ Using anterior OCT, we found that the thickness of the right cornea was almost the same as the normal left cornea, implying that the function of the $\mathrm{Na}^{+} / \mathrm{K}^{+}$ATPase pump, and the barrier of endothelial cell was being kept at a normal range and maintaining the thickness of the cornea. However, endothelial cells never regenerate and their number decreases with age. The age of the patient is 15 and she needs long-term observation, especially concerning the density of her endothelium. Usually, PCV does not affect visual acuity. $\mathrm{Up}$ to now, the rate of decrease in cell density of a normal endothelium is $\sim 0.6 \%$ per year. ${ }^{8}$ We need to pay attention in the follow-up examination not only to the natural course of the decreasing cell density in the endothelium but also to hypoxic and mechanical stress to endothelial cells, which occurs as a result of wearing contact lens and eye surgery to prevent the bullous keratopathy.

Using the HRTII-RCM, for the first time, it was possible to observe endothelial cells in rounded dark areas, hyperreflective linear lesions, and acellular hyporeflective layers. There was also no detected increase of density and brightness of keratocytes; in addition the nerve plexus showed a normal shape. Anterior OCT revealed protuberances toward the anterior chamber and no difference in the thickness of either cornea. In this case, we should observe the density of the corneal endothelial cells carefully.

\section{Disclosure}

The authors report no conflicts of interest in this work.

\section{References}

1. Schnyder W. Herpetiforme Erkrankung der Hornhautrückfläche [Herpes corneae posterior]. Klin Mbl Augenheilk. 1924;73:385-390.

2. Pardos GJ, Krachmer JH, Mannis MJ. Posterior corneal vesicles. Arch Ophthalmol. 1981;99(9):1573-1577.

3. Harada T, Tanaka H, Ikema T, Asakura K, Miura M, Ozeki Y. Specular microscopic observation of posterior corneal vesicles. Ophthalmologica. 1990;201(3):122-127.

4. Patel DV, Grupcheva CN, McGhee CN. In vivo confocal microscopy of posterior polymorphous dystrophy. Cornea. 2005;24(5):550-554.

5. Grupcheva CN, Chew GS, Edwards M, Craig JP, McGhee CN. Imaging posterior polymorphous corneal dystrophy by in vivo confocal microscopy. Clin Experiment Ophthalmol. 2001;29(4):256-259.

6. Cheng LL, Young AL, Wong AK, Law RW, Lam DS. Confocal microscopy of posterior polymorphous endothelial dystrophy. Cornea. 2005;24(5):599-602.

7. Babu K, Murthy KR. In vivo confocal microscopy in different types of posterior polymorphous dystrophy. Indian J Ophthalmol. 2007;55(5):376-378.

8. Bourne WM, Nelson LR, Hodge DO. Central corneal endothelial cell changes over a ten-year period. Invest Ophthalmol Vis Sci. 1997;38(3):779-782.
Clinical Ophthalmology

\section{Publish your work in this journal}

Clinical Ophthalmology is an international, peer-reviewed journal covering all subspecialties within ophthalmology. Key topics include: Optometry; Visual science; Pharmacology and drug therapy in eye diseases; Basic Sciences; Primary and Secondary eye care; Patien Safety and Quality of Care Improvements. This journal is indexed on

Submit your manuscript here: http://www.dovepress.com/clinical-ophthalmology-journal

\section{Dovepress}

PubMed Central and CAS, and is the official journal of The Society of Clinical Ophthalmology (SCO). The manuscript management system is completely online and includes a very quick and fair peer-review system, which is all easy to use. Visit http://www.dovepress.com/ testimonials.php to read real quotes from published authors. 